\title{
Two observations of the hematology of women
}

\author{
Guillermo J. Ruiz-Argüelles* \\ Hematology Center and Internal Medicine of Puebla, Puebla, Mexico
}

When Professor David Gomez-Almaguer asked me to write an Editorial note for this issue of Medicina Universitaria, he mentioned that I should address salient features of the hematological aspects of women; accordingly, I decided to mention two hematological features of women, focusing on the practice of hematology in on our country.

\section{Anemia}

In Mexico and most countries worldwide, the most frequent cause of anemia in women is iron deficiency, due mainly to menometrorrhagia. Most general practitioners and even hematologists are unaware of the fact that iron polymaltose is poorly absorbed from the gastrointestinal tract, and as a result, they frequently indicate treatment with this iron presentation which does not resolve the anemia. The number of patients who visit the hematologist because they have "iron-refractory anemia" is very large, and the story of Mexican hematologists simply switching from iron polymaltose to another iron salt (fumarate or sulfate) solves the problem. Despite the fact that this observation has been widely published ${ }^{1,2}$, most Mexican physicians are not aware of this knowledge. The argument of "this patient does not absorb iron" is very frequent when these patients are unnecessarily referred to the hematologist. In developed counties, iron polymaltose has been withdrawn from the market ${ }^{1,2}$, which is not the case in Mexico.

\section{Recurrent fetal loss}

Miscarriages in Mexico occur in $12-13 \%$ of healthy women ${ }^{3}$. This figure goes up to $32 \%$ in women with the sticky platelet syndrome (SPS), a statistically significant difference. The SPS has been recognized as the most frequent cause of recurrent fetal loss in our country ${ }^{3}$, more frequent than even other autoimmune or infectious conditions, such as antiphospholipid syndrome or infections by toxoplasma, rubella, cytomegalovirus, or herpes ${ }^{3}$. The proper identification of SPS followed by appropriate treatment leads into the course of successful pregnancies in these women, provided they are given antiplatelet drugs, mainly aspirin, throughout the whole pregnancy. A simple and effective therapeutic approach based on this knowledge allows happy pregnancies for many Mexican women.

\section{Conclusion}

After many years practicing hematology, we have been able to identify some features of certain hematological aspects in Mexican women which may be different from those observed in other parts of the world. Physicians in Mexico should be aware of these different features of some female hematological conditions, to offer them adequate treatments and avoid unnecessary studies and medical actions.

Finally, in this issue of Medicina Universitaria, three articles are presented in relation to pregnancy and

\section{Correspondence:}

*Guillermo J. Ruiz-Argüelles

E-mail: gruiz1@ clinicaruiz.com
Available online: $27-05-2019$

Date of reception: 19-03-2019

Date of acceptance: 19-03-2019

DOI: 10.24875/RMU.M19000030
Medicina Universitaria. 2019;21(1):2-3 www.medicinauniversitaria.org CC BY-NC-ND license (http://creativecommons.org/licenses/by-nc-nd/4.0/). 
hematological diseases. Thrombocytopenia, thrombosis, and leukemia are discussed; these are very important subjects in this field, and it is necessary for the practicing physician to be aware of the particularities of the mentioned conditions during pregnancy, and their possible consequences for the developing fetus.

\section{References}

1. Ruiz-Argüelles GJ, Díaz-Hernández A, Manzano C, Ruiz-Delgado GJ. Ineffectiveness of oral iron hydroxide polymaltose in iron-deficiency anemia. Hematology. 2007;12:255-6.

2. Ruiz-Argüelles GJ. Iron deficiency anemia in low- and middle-income countries. Blood. 2013;122:2289.

3. Ruiz-Delgado GJ, Cantero-Fortiz Y, Mendez-Huerta MA, et al. Primary thrombophilia in mexico XII: miscarriages are more frequent in people with sticky platelet syndrome. Turk J Haematol. 2017;34:239-43. 